\title{
Suspected child abuse: cost in medical time and finance
}

\author{
C L Summers, E M Molyneux
}

\begin{abstract}
In a prospective study the number of children attending the Royal Liverpool Children's Hospital (RLCH) for examination after allegations of child abuse, and the type of abuse involved, was recorded from July to December 1990. The cost to the hospital of these examinations and initial investigations was assessed. The study was carried out in the major and minor accident and emergency departments and the Rainbow Centre of the RLCH. In six months 181 children were examined. Cases of sexual abuse and nonaccidental injury were seen in equal numbers. Girls outnumbered boys and $60 \%$ were referred by social services. The costs over the six month period were $£ 31739$. The minimum projected annual cost is $£ 63500$. We conclude that the cost of running an effective service for the initial assessment of children who are possible victims of child abuse is considerable in practical terms and in medical time.
\end{abstract}

There have been many studies of the physical and emotional consequences of child abuse, ${ }^{1-4}$ but little attention has been given to the financial cost of child abuse for the health service and, in turn, for society. The cost in medical time is considerable but has not been documented. This study was undertaken as an audit of the problem of child abuse at the Royal Liverpool Children's Hospital (RLCH). We monitored all patients seen with suspected child abuse over a six month period, and assessed the financial implications for the hospital.

The policy for managing child abuse in Liverpool has been written at the direction of, and approved by, the Area Child Protection Committee (ACPC). It is contained in a child protection manual. This policy follows the guidelines recommended by such documents as Working Together. ${ }^{5}$ It is followed by all the agencies involved in the diagnosis and management of children suspected of child abuse and emphasises the multidisciplinary approach to such children. If an allegation of non-accidental injury comes to social services a social worker, through a senior child protection consultant, investigates the allegation. She may liaise with her counterpart in the police force. One or other of these agencies will contact a paediatrician experienced in child abuse work to examine the child. In cases of non-accidental injury where a criminal investigation is likely to take place, the police may request that a police surgeon (usually a local general practitioner) be present at the examination with the paediatrician.
Equally, the paediatrician may request that a police surgeon attend for such a case. In cases of suspected child sexual abuse a social worker and a designated member of the police force, who are both members of the child protection team, together review the allegation, interview the child, and ask for a joint examination of the child by a police surgeon and a paediatrician. In most cases of non-accidental injury where the alleged perpetrator is a member of the family, siblings are examined for evidence of injury. In cases of suspected child sexual abuse the siblings are examined if there is any suspicion of their involvement. If they are involved they become index cases.

Teachers, general practitioners, and other professional carers for a child are advised to contact social services immediately they suspect a child of child abuse. If the injuries are severe they are asked to bring the child directly to hospital to see a paediatrician.

At hospital, when a child is seen or admitted for another cause, but child abuse is suspected, there are clear guidelines for staff to notify the consultant in charge and the hospital social workers.

The doctors who examine children for child sexual abuse are paediatricians. The senior staff in the accident and emergency department are two experienced paediatrically trained consultants who have attended training sessions in forensic medicine, and one clinical assistant with over 20 years experience in this field. Both consultants in the accident and emergency department are members of the ACPC of either Liverpool or South Sefton. All three doctors have considerable experience in the problem of child abuse. Medical paediatric registrars, under the supervision of their own consultants, see children suspected of non-accidental injury.

Children who fail to thrive are investigated by paediatricians. Emotionally abused children are referred to a mental health team comprising psychologists, psychiatrists, and psychiatric social workers.

In June 1990 a centre for the examination of suspected cases of child abuse was opened in the RLCH, at Alder Hey, Liverpool. The centre is adjacent to the accident and emergency department and consists of a reception room, office, three interview rooms-one equipped with a video recording system-and an examination room with bathroom attached. The unit is known as the Rainbow Centre and is staffed by a full time administrator, a part time secretary, and a staff grade nurse who works both in the centre and in the accident and emergency department. 
When it was first opened the Rainbow Centre was used solely for suspected sexual abuse, while physically abused children were seen in the accident and emergency department. Since February 1991 all children suspected of child abuse have been seen in the centre.

The accident and emergency unit of the RLCH is on two sites. The major unit is at Alder Hey and gives a 24 hour service with the full back-up facilities of a paediatric hospital: 53000 new patients were seen in 1990 . The inner city department is a minor casualty service

Table 1 Type of suspected child abuse

\begin{tabular}{llllllr}
\hline & $\begin{array}{l}\text { Child } \\
\text { sexual } \\
\text { abuse }\end{array}$ & $\begin{array}{l}\text { Non-accidental } \\
\text { injury }\end{array}$ & $\begin{array}{l}\text { Child sexual } \\
\text { abusel } \\
\text { non-accidental } \\
\text { injury }\end{array}$ & Neglect & Siblings & Total \\
\hline Boys & 17 & 32 & 1 & 0 & 26 & 76 \\
Girls & 52 & 36 & 2 & 1 & 14 & 105 \\
Total & 69 & 68 & 3 & 1 & $40^{*}$ & 181
\end{tabular}

*Of all siblings examined, 34 for non-accidental injury, four child sexual abuse, and two child sexual abuse/non-accidental injury.

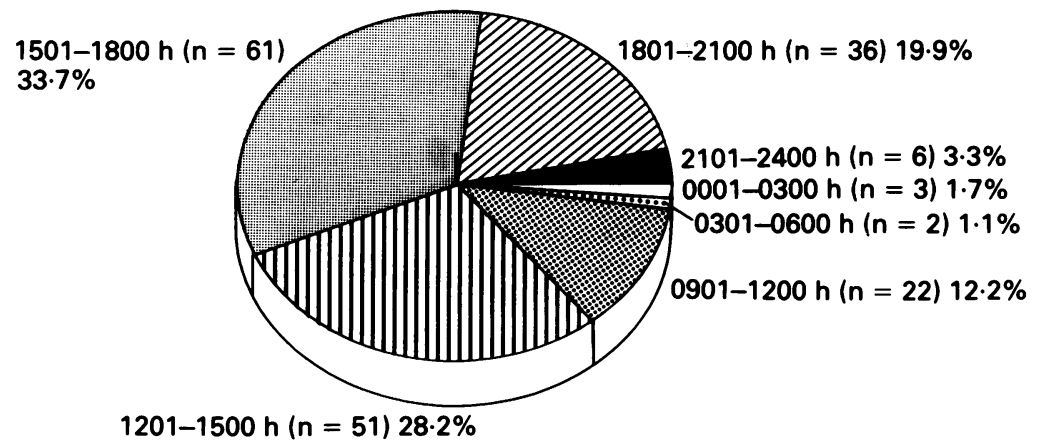

Figure 1 Time of examination in child abuse $(n=18)$.

Table 2 Age and reason for referral $(n=181)$

\begin{tabular}{ccclccc}
\hline $\begin{array}{l}\text { Age } \\
\text { (years) }\end{array}$ & $\begin{array}{l}\text { Child } \\
\text { sexual } \\
\text { abuse }\end{array}$ & $\begin{array}{l}\text { Non-accidental } \\
\text { injury }\end{array}$ & $\begin{array}{l}\text { Child sexual } \\
\text { abusel } \\
\text { non-açcidental } \\
\text { injury }\end{array}$ & Neglect & Siblings & Total \\
\hline $0-1$ & 0 & 5 & 0 & 1 & 4 & 10 \\
$>1-4$ & 31 & 27 & 1 & 0 & 21 & 80 \\
$5-9$ & 19 & 20 & 2 & 0 & 13 & 29 \\
$10-14$ & 15 & 12 & 0 & 0 & 0 & 8 \\
$15 / 16$ & 4 & 4 & 0 & 0 & & \\
\hline
\end{tabular}

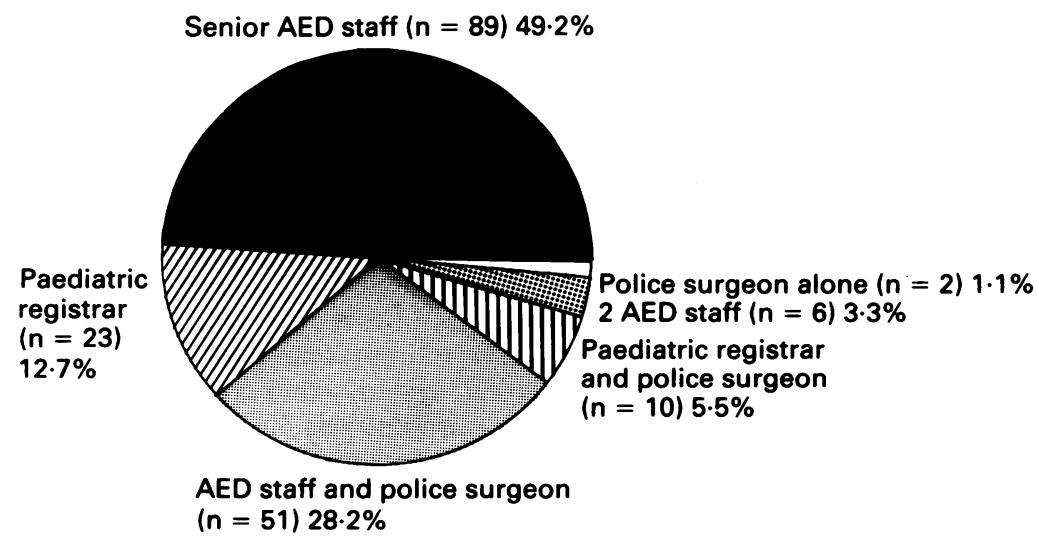

Figure 2 Medical examiners in child abuse $(n=181) . A E D=$ accident and emergency department. open daily from 9 am to $10 \mathrm{pm}$ : 12000 new patients attended in 1990. The two accident and emergency departments and the Rainbow Centre receive children from Liverpool, South Sefton, St Helens, and Knowsley and even further afield. The total population of children under 16 years of age in these areas is 227954 . Not all injured or abused children from this area are seen in the RLCH: staff in other hospitals and police stations within the area also see and diagnose child abuse.

\section{Methods}

From 1 July to 31 December 1990 a proforma was completed by the examining doctor for all cases of suspected child abuse. Information recorded included the age and sex of the child, the reason for referral and by whom referred, the date and time of examination and its findings, any investigations performed, and where the child went after leaving the hospital. For a 13 week period, 7 July 1990 to 18 October 1990 , details included the time it took for an examination to be carried out.

\section{Results}

During the six month study period 181 children were examined for possible child abuse (table 1). There were 105 (58\%) girls and 76 (42\%) boys. Table 1 shows the sex of the children and the reasons for their examinations. Of the 181 children, $107(60 \%)$ were referred to the hospital by social services, $41(22 \%)$ by the police, and $12(6 \%)$ by general practitioners. Ten $(5 \%)$ were brought directly by parents, and three $(2 \%)$ by other relatives. Seven $(4 \%)$ were referred to the accident and emergency department by other hospital staff. One child was self referred and one was sent to the unit by the National Society for Prevention of Cruelty to Children (NSPCC). Altogether $153(85 \%)$ of the children were accompanied to the hospital by a parent, four came with another relative, and 24 were brought by an adult other than a parent or relative; this was usually a social worker.

The distribution of attendances by month was fairly constant with peaks in July and September (41/month compared with $23 /$ month in October to December). Children were seen evenly throughout the week from Monday to Friday (mean 1.5 patients per day) but fewer presented at weekends ( 0.6 per day). The time of day of examinations is shown in fig 1 , and the ages of the children and the indication for the examination in table 2.

Fifty eight children were seen in the inner city minor casaulty department, 76 in the Rainbow Centre, and 47 at Alder Hey accident and emergency department. The examinations were carried out by senior accident and emergency staff, police surgeons, and medical paediatric registrars. Figure 2 shows the number of children examined by members of each group of practitioners.

The average time taken to examine a child suspected of child sexual abuse was $\mathbf{5 0}$ minutes (range 20-235 minutes) and for non-accidental injury was 59 minutes (range 15-220 minutes). 
In possible cases of non-accidental injury the examination confirmed the suspicions in $54 \%$ of cases (table 3 ). In child sexual abuse $13 \%$ had clear physical findings of the abuse. A number of other physical findings came to light: some of these were suggestive of child sexual abuse; some had been confused with non-accidental injury (table 4). No sibling who was examined was found to have suffered child abuse.

The majority of children $(71 \%)$ required no investigation beyond a careful examination. Others required a variety of investigations (table 5). Altogether $136(75 \%)$ children went home after being examined, 13 (7\%) were admitted, $10(5 \cdot 5 \%)$ were subject to a place of safety order, nine $(5 \%)$ went into social services care, and nine (5\%) went into foster care. Two children went home with a relative and one child went home with a friend. One child aged 2.5 years who had multiple injuries including a fractured skull and ruptured liver was dead on arrival in minor casualty.

THE COST OF CHILD ABUSE EXAMINATIONS

The Rainbow Centre carries the annual salary costs of the part time clerk-typist $(£ 4558 \cdot 38)$, the administrator ( $£ 13515)$, a staff nurse

Table 3 Results of examination in child abuse $(n=181)$

\begin{tabular}{|c|c|c|c|c|c|c|}
\hline & $\begin{array}{l}\text { Child } \\
\text { sexual } \\
\text { abuse }\end{array}$ & $\begin{array}{l}\text { Non-accidental } \\
\text { injury }\end{array}$ & $\begin{array}{l}\text { Child sexual } \\
\text { abusel } \\
\text { non-accidental } \\
\text { injury }\end{array}$ & Neglect & Siblings & Total \\
\hline $\begin{array}{l}\text { Diagnosis confirmed } \\
\text { Not confirmed }\end{array}$ & $\begin{array}{r}9 \\
60\end{array}$ & $\begin{array}{l}38 \\
30\end{array}$ & $\begin{array}{l}1 \\
2\end{array}$ & $\begin{array}{l}0 \\
1\end{array}$ & $\begin{array}{r}0 \\
40\end{array}$ & $\begin{array}{r}48 \\
133\end{array}$ \\
\hline
\end{tabular}

Table 4 Other physical findings

\begin{tabular}{|c|c|}
\hline $\begin{array}{l}\text { Miscellaneous diagnoses in non-accidental } \\
\text { injury }\end{array}$ & $\begin{array}{l}\text { Flea bites }(n=1) \\
\text { Birthmark }(n=1) \\
\text { Henoch-Schönlein purpura }(n=1)\end{array}$ \\
\hline $\begin{array}{l}\text { Miscellaneous diagnoses in child sexual abuse } \\
\text { (Some of these fingings would corroborate } \\
\text { a diagnosis of child sexual abuse but not be } \\
\text { conclusive evidence for the diagnoses) }\end{array}$ & $\begin{array}{l}\text { Threadworms }(n=4) \\
\text { Redness of perineum ( } n=4) \\
\text { Vulvovaginitis }(n=4) \text {, one with introitus at upper } \\
\text { limit of normal for age } \\
\text { Labial adhesions }(n=2) \\
\text { Adhesions of fourchette }(n=2) \\
\text { Candida }(n=1) \\
\text { Vaginal discharge }(n=1) \\
\text { Ovarian cyst }(n=1) \\
\text { Lichen sclerosis et atrophica }(n=1) \\
\text { Bruised inner thigh }(n=1) \\
\text { Slight vestibular swelling }(n=1) \\
\text { Clear history of fingering }(n=1) \\
\text { Anal dilatation due to constipation }(n=1) \\
\text { Vaginal bruising consistent with accidental injury } \\
\text { (n=1) } \\
\text { Pubic hairs present, different from child's }(n=1) \\
\text { Child appeared 'knowing' in examination }(n=1)\end{array}$ \\
\hline
\end{tabular}

Table 5 The investigations and their cost in child abuse

\begin{tabular}{lcl}
\hline Investigation & No & Cost \\
\hline None & 129 & \\
Radiograph of injured site & 20 & $£ 400$ \\
Skeletal survey & 21 & $£ 1050$ \\
Photography & 23 & $£ 276$ \\
Full blood count and clotting studies & 27 & $£ 356.40$ \\
Analysis of midstream specimen of urine & 11 & $£ 44$ \\
Swabs & 1 & $£ 6.45$ \\
Full forensic investigation & 2 & \\
& Total $=£ 2132.85$
\end{tabular}

A number of investigations were carried out 'out of hours' and this increased their cost considerably.
(£13 164), and seven senior casualty sessions/ week ( 20 062). Incidental expenses run to $£ 550 /$ year. During the six month study period additional medical time cost $£ 3680$. Investigations totalled $£ 2132.85$ in the six month period. The hospital 'hotel' bill for 64 nights at $£ 180$ /day was $£ 11$ 520. These costs total $£ 31738.53$ over the study period giving an estimated annual cost to the Rainbow Centre and hospital of $£ 63500$.

\section{REASON FOR REFERRAL}

In cases of non-accidental injury an injury may have been noted to have inadequate accidental explanation or an admission of intentional injury made. Many parents of children who were on the child protection register brought the attention of social workers to all the injuries of their children. An examination of the child was usually arranged at the hospital. This practise, and the routine examination of all siblings, led to many examinations failing to confirm nonaccidental injury. In suspected cases of child sexual abuse $29(42 \%)$ were investigated after comments made by the children themselves; $45 \%$ of these children were under 5 years of age. Twelve were seen because of concern about their behaviour, 12 due to concern for their siblings and indirectly for the children themselves. Eight girls were complaining of perineal soreness. Seven children were examined after a parent had made allegations of possible child sexual abuse to the child; four were due to continuing concerns regarding the family, and one was referred from another district for a second opinion before a court case.

\section{Discussion}

INCIDENCE

In England and Wales four children die as a result of child abuse each week and 40000 children are on the child protection register. ${ }^{5}$ During the six month period of this study, 181 children with alleged child abuse were seen in an urban paediatric hospital. The corresponding figure for July-December 1987 was 106 (1987 was chosen for comparison as the year predates the Cleveland inquiry that highlighted the problems of child abuse, and child sexual abuse in particular, in our society).

Several studies have noted an increase in allegations of child abuse in recent years. Meadow states that there has been an increase in child abuse of 4 to 5 -fold over the last decade. ${ }^{5}$ The NSPCC has collected annual figures for many years and reported that from 1983-7 (preCleveland) there was an increase in reported child sexual abuse from $0.08-0.65 / 1000$ children/year. ${ }^{6}$

In our study the referrals for child sexual abuse equal those for non-accidental injury. This probably reflects the frequency with which child sexual abuse is referred to the hospital. Other forms of child abuse may be dealt with in greater numbers by local agencies. Girls outnumber boys in child sexual abuse $(68: 44)$ in line with the national trend. In our study they outnumbered boys in non-accidental injury by 37 to 32 . 
COLLABORATION BETWEEN SERVICES

Most of the children $(60 \%)$ were referred by social services. This reflects the policy of involving social workers at an early stage in allegations of child abuse. The police referred $22 \%$ of cases. These referrals, usually for child sexual abuse, were made after consultation between police and social workers and involved an examination carried out jointly by a paediatrician and police surgeon.

\section{COST IN TIME}

Altogether $94 \%$ of the children were seen between the hours of 9 am and $9 \mathrm{pm} ; 75 \%$ were seen between $9 \mathrm{am}$ and $6 \mathrm{pm}$. Most of the examinations were carried out with prior arrangement so that children would not have to wait to be seen and investigations by the social services could be completed. Every effort was made not to examine children late in the evening, but sometimes distraught parents were insistent that their child be examined without any delay. Sometimes social services and police found it difficult to complete their investigations until the family were returned home from work or school.

Senior staff in the accident and emergency department saw $81 \%$ of the children which took 206 hours of clinical time, not accounting for time taken in writing reports, attending case conferences, and court appearances. This time commitment by medical staff needs to be taken into account when staffing levels in such a department are reviewed.

\section{FINANCIAL COST}

To provide a separate location for assessing victims of possible child abuse inevitably involves expense. The Rainbow Centre is a purpose designed area which fulfils the Department of Health guidelines of interagency cooperation in child abuse cases ${ }^{7}$ in aiming to provide a sympathetic and peaceful atmosphere where the children can be examined and where their problems can be discussed with the police and social workers and doctors'. 8 Bamford and Roberts state that examinations for child sexual abuse 'should be conducted in absolute privacy in an environment where the child can be comfortable." 9 The centre allows for a single joint examination by relevant staff in a room suitably equipped for all types of examination, 'so that the number of examinations to which a child is subjected is kept to a minimum'. ${ }^{10}$ Although $70 \%$ of cases needed no further investigations, tests carried out on the other children were expensive (total £2133). The tests requested out of hours increased the cost of each request threefold.

The minimum annual costs to this hospital of $£ 63500$ take no account of capital costs to provide the centre and its maintenance. Further uncosted expenses include attendance at case conferences, court appearances, and the time taken in preparing reports for these. The police incur the costs of forensic examinations and of attendance of the police surgeon at examinations. The costs to the hospital have not included any medical treatments required by the children. The cost of follow up with counselling and other support has not been estimated.

\section{CONCLUSION}

The diagnosis and investigation of child abuse is a difficult and important area of paediatrics. It is expensive, not only in financial terms but also in time. This work is done by experienced staff; in the RLCH $82 \%$ of child abuse work in the six month study period was done by senior casualty staff. To ease this burden on two or three members of staff the suspected cases of nonaccidental injury are now seen by paediatric medical registrars under the supervision of their paediatric consultant. Child abuse is demanding in time and energy of staff of the welfare agencies and in particular the social services. It is important to develop and maintain a multidisciplinary approach in a suitable setting such as the Rainbow Centre, but the financial and time commitment by medical staff and their institutions needs to be acknowledged and given support.

1 Skuse DH Emotional abuse and neglect. $B M 7$ 1989;298: 1692-4.

2 Skuse DH. Emotional abuse and delay in growth. $B M \mathcal{F}$ 1989;299:113-5.

3 Meadow R. Munchausen syndrome by proxy. $B M \mathcal{I}$ 989;299:248-50.

4 Nicol AR. Role of the child psychiatry team in child abuse. $B M \mathcal{F}$ 1989;299:451-2.

5 Department of Health and Welsh Office Publication. Working together. London: HMSO 1991

Meadow R. Epidemiology of child abuse. BMF 1989;298 727-30.

The Rainbow Centre. The Rainbow Centre leaflet. Liverpool: The Royal Liverpool Children's Hospital, 1990.

8 Creighton SJ, Noyes P. Child abuse trends in England and Wales 1983-87. London: NSPCC, 1989.

9 Bamford F, Roberts R. Child sexual abuse I. BMF 1989;299:312-3.

10 Department of Health. Diagnosis of child sexual abuse. Evidence for doctors. London: HMSO 1988.

\section{Commentary}

Child protection work is difficult to cost as the task is a multiagency one. The medical time involved is only one part of the overall expense. Summers and Molyneux have audited the cost of medical examination in units in their hospital. During the six month study period a diagnosis of abuse was confirmed in 48 out of 181 referred children. For a catchment area of total child population 227954 this seems a low figure given that Liverpool has areas of severe urban deprivation. The absence of cases of neglect diagnosed during this period is surprising and reminiscent of figures produced for Glasgow in the 1980s. ${ }^{1}$

There is apparently a low level of confirmation of diagnosis, especially in the suspected sexual abuse cases $(26.5 \%$ of total referrals, $13 \%$ of sexual abuse referrals confirmed). However it is not clear what model of diagnosis is being used or what happened to the 60 children referred with suspicions of sexual abuse where the diagnosis was 'not confirmed'.

The question has to be asked whether the social services and police in Liverpool are poor in their selection of cases referred, or whether 